\title{
Procedural Results and In-Hospital Adverse Outcomes Following Multivessel Percutaneous Coronary Intervention (PCI)
}

\author{
Md. Harisul Hoque ${ }^{1}$, Sufia Rahman ${ }^{2}$, Md. Abu Siddique ${ }^{1}$, Syed Ali Ahsan ${ }^{1}$, C M Ahmed ${ }^{1}$, \\ S M Mustafa Zaman'1, Manzoor Mahmood ${ }^{1}$, Mukhlesur Rahman ${ }^{1}$, Md. Khurshed Ahmed ${ }^{1}$ \\ ${ }^{1}$ Department of Cardiology, Bangabandhu Sheikh Mujib Medical University, Shahbag, Dhaka \\ ${ }^{2}$ Euro Bangla Heart Hospital, Dhanmondi, Dhaka \\ Address for Communication \\ Dr. Md. Harisul Hoque, Assistant Professor \\ Department of Cardiology, Bangabandhu Sheikh Mujib Medical University, Shahbag, Dhaka. \\ E-mail: harishoque@yahoo.com
}

\begin{abstract}
Several Studies have reported specific factors associated with increased risk of adverse outcome following balloon angioplasty. These factors include advanced age, female Sex, unstable angina, congestive heart failure, diabetes and multivessel Coronary artery disease. By this time, Studies have been shown the remarkable procedural success \& minimum adverse outcomes following multivessel stenting. This comparative observational study shows no death, procedural MI, tamponade, cerebrovascular accident, heart failure or cardiogenic shock, vascular access site complications like bleeding, A-V fistula in any group (single vessel stenting vs multivessel stenting). However, minor adverse events occurred at an overall rate of $6 \%$ in single vessel stenosis (SVS) group \& $12 \%$ in multivessel stenosis (MVS) group. Procedural results were also similar in both groups. Angiographic success of 100\% in the SVS group \& $98 \%$ in the MVS group noted. The difference in the outcomes were between the two groups was not significant.
\end{abstract}

Key Words: Adverse Outcomes, Multivessel Coronary Stenting, Procedural Results,

\section{Introduction}

Patient with multivessel coronary artery disease will often be eligible for either catheter-based intervention or Coronary Artery Bypass graft $(\mathrm{CABG})^{1}$. Before stent era, multivessel angioplasty had less favourable procedural results compared with single vessel interventions and longterm outcomes were compromised by the cumulative effect of restenosis ${ }^{6-9}$. Consequently, the results of randomized trials comparing angioplasty with CABG differed markedly in the need for subsequent revascularization procedures and angina relief, in favour of the surgical approach ${ }^{10}$. However, those randomized trials were conducted before stents were available to improve angioplasty results and reduce late restenosis ${ }^{11}$. Patients with higher pre-procedural jeopardy scores were shown to have a greater likelihood of cardiovascular collapse when abrupt vessel closure occurred during percutaneous Transluminal Coronary Angiography (PTCA $)^{12}$. On the other hand the major advantage of PCI is its relative ease of use, avoiding general anesthesia, thoracotomy, extracorporal circulation, CNS complications, and prolonged convalescence. Repeat PCI can be performed more easily than repeat bypass surgery, and revascularization can be achieved more quickly in emergencies ${ }^{13}$.
This study was designed to assess procedural success \& inhospital adverse outcomes following multivessel stenting

\section{Patients and Method}

The study was conducted in the department of Cardiology of National Institute of Cardiovascular Diseases (NICVD), Sher-e-Bangla Nagar, Dhaka. It was a prospective non-randomized comparative observational study using consecutive patients undergoing multivessel stenting as a single stage procedure. The study was conducted between July 2002 to June 2003. The study population consisted of 100 patients who had undergone stent based angioplasty procedure. The selected patients were divided into two groups according to the number of treated vessels (one group with single vessel stenting and another group with two or more vessel stenting). Total 100 patients enrolled in this study mean age group $49.96( \pm 10.2)$ in single vessel group $(\mathrm{n}=50)$ while $53.10( \pm 10.3)$ in multivessel group $(\mathrm{n}=50)$. Gender distribution in single vessel group was 46.4 while in multivessel group it was 48.2.

Patients were informed about the benefits, risks and possible alternative therapies following which written consent was obtained from patients willing to participate in the study. 


\section{Inclusion Criteria:}

Patient with two or three vessel disease requiring stent implantation during a single session.

All indication for stent use (elective, provisional and urgent) were included in the study.

EF\% - > 25\% (by Echocardiography).

\section{Exclusion Criteria:}

1. Patients with left main disease (protected and unprotected).

2. Patients requiring staged procedures.

3. Patients with prior CABG or prior PTCA.

4. Patients having any severe systemic illness (liver/ kidney disease).

5. Patients with uncontrolled CHF (NYHA stage III \& IV)

6. Patients with diffuse coronary arterial disease not suitable for CABG or PTCA.

7. Patients with EF\% $<25 \%$ by Echocardiography.

\section{Methodology}

All patients had pre-intervention and post intervention 12 lead ECG. Blood samples were routinely taken from all patients every 8 hourly for 24 hours following the procedure for CK-MB. Following the initial balloon angioplasty, coronary stents were implanted. Adjunct high-pressure balloon inflation was added after initial stent deployment in every patient. In suitable cases direct balloon mounted stenting were done. Procedural results and adverse outcomes are defined according to guidelines of American College of Cardiology as described below:-

Acute Outcome - Definition of PTCA Success: Acute outcome of PTCA is measured the success of the procedure and procedural complications. A successful PTCA is defined by angiographic, procedural and clinical criteria.

1. Angiographic Success. A successful PCI produces substantial enlargement of the lumen at the target site. The consensus definition prior to the widespread use of stents was the achievement of a minimum stenosis diameter reduction to $<50 \%$ in the presence of grade 3 TIMI flow. However, with the advent of coronary stents, a minimum stenosis diameter reduction to $<20 \%$ has been the clinical benchmark of an optimal angiographic result.

2. Procedural Success. A successful PCI should achieve angiographic success without in-hospital major clinical complications (e.g., death, MI, emergency coronary artery bypass surgery) during hospitalization the definition of procedure-related MI has been debated. The development of Q-waves in addition to a threshold value of CK elevation has been commonly used. However, the significance of enzyme elevations in the absence of Q-waves remains a subject of investigation and debate. Several reports have identified non-Q-wave MIs with CK-MB elevations 3 to 5 times the upper limit of normal as having clinical significance. Thus a significant increase in CK-MB without Q-waves is considered by most to qualify as an associated complication of PCI.

3. Clinical Success. In the short term, a clinically successful PCI includes anatomic and procedural success with relief of signs and/or symptoms of myocardial ischemia after the patient recovers from the procedure.

Procedural Complications: procedural complications are divided into six basic categories: death, MI, emergency coronary artery bypass graft (CABG) surgery, stroke, vascular access site complications, and contrast agent nephropathy.

Death - Patient died during this hospitalization.

Periprocedural MI - The new presence of an MI as documented by at least 1 of the following criteria:

1. Evolutionary ST-segment elevations, development of new Q-waves in 2 or more contiguous ECG leads, or new or presumably new LBBB pattern on the ECG.

2. Biochemical evidence of myocardial necrosis; this can be manifested as 1 ) $\mathrm{CK}-\mathrm{MB} \geq 3$ the upper limit of normal or if $\mathrm{CK}-\mathrm{MB}$ not available 2) total $\mathrm{CK} \geq 3$ upper limit of normal

\section{Results}

Table I. Comparison of the Demographic and Clinical Characteristics of the Study patients $(n=100)$

\begin{tabular}{|c|c|c|c|}
\hline Variables & $\begin{array}{l}\text { Single Venisel } \\
\text { Creup (s-55) }\end{array}$ & $\begin{array}{c}\text { Multi Veased } \\
\text { Giroep (a-50) }\end{array}$ & $P$ Vahe \\
\hline $\begin{array}{l}\text { Age, years } \\
\text { Mend(ID) }\end{array}$ & $496( \pm 10.2)$ & $53.10(+10.3)$ & 0128 \\
\hline $\begin{array}{l}\text { Cernier } \\
\text { Mtak Fermale }\end{array}$ & $46-4$ & $48: 2$ & 6678 \\
\hline 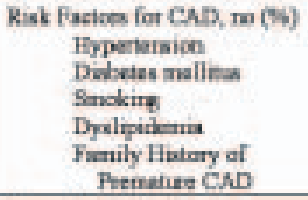 & $\begin{array}{l}17(34) \\
2 x(4) \\
13(34) \\
1002) \\
200\end{array}$ & $\begin{array}{l}28(56) \\
1836) \\
11(23) \\
204) \\
1(20) \\
\end{array}$ & $\begin{array}{l}0064 \\
0541 \\
1060 \\
0059 \\
1000\end{array}$ \\
\hline Fior ML no (\$s) & $\mathbf{2 x} \times \mathbf{W}$ & $25(50)$ & 6547 \\
\hline 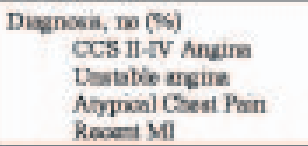 & $\begin{array}{l}2 x(46) \\
2 x(46) \\
406)\end{array}$ & $\begin{array}{l}30(52) \\
19(38) \\
1000) \\
4(0)\rangle\end{array}$ & 6095 \\
\hline
\end{tabular}

$\mathrm{SD}=$ Standard Deviation, $\mathrm{CAD}=$ Coronary Artery Disease, $\mathrm{CSA}=$ Chronic Stable Angina, $\mathrm{CCS}=$ Canadian Cardiovas-cular Society Angina Grading. $* P$ value $<0.05$ was considered significant.

Comparison of In-hospital Adverse Events and hospital stay of the study population

Analysis of the incidence of Major Adverse Cardiac and Cerebrovascular Events (MACCE) showed that there was no such event in the index population. 
Table II. Comparison of the In-hospital adverse events and outcome of study patients.

\begin{tabular}{|c|c|c|c|}
\hline \multirow[t]{2}{*}{ Variables } & \multicolumn{2}{|l|}{ Stedy Group } & \multirow[t]{2}{*}{ PValue } \\
\hline & $\begin{array}{l}\text { Simgle Veasel } \\
\text { Suenting } \\
n-50(\%)\end{array}$ & $\begin{array}{l}\text { Maltivesas! } \\
\text { Stenting } \\
n-50(\%)\end{array}$ & \\
\hline 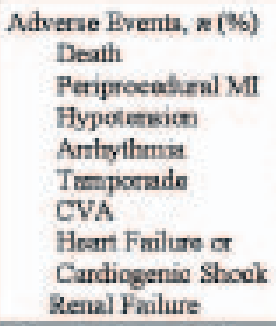 & $\begin{array}{l}0 \\
0 \\
1(2 \%) \\
2(45) \\
0 \\
0 \\
0 \\
0\end{array}$ & $\begin{array}{l}0 \\
0 \\
2(196) \\
3(6 \%) \\
0 \\
0 \\
0 \\
1(2 \%)\end{array}$ & $\begin{array}{l}- \\
0558 \\
0646 \\
- \\
0.645\end{array}$ \\
\hline $\begin{array}{l}\text { Vascular Ausess Sote } \\
\text { Complivations } \\
\text { Biooding/fiematoma } \\
\text { Ooclusion } \\
\text { Dissection } \\
\text { AV Fistula }\end{array}$ & $\begin{array}{l}2(4 w) \\
0 \\
0 \\
0\end{array}$ & $\begin{array}{l}3(6 \%) \\
0 \\
0 \\
0\end{array}$ & $\begin{array}{l}0.646 \\
- \\
-\end{array}$ \\
\hline $\begin{array}{l}\text { Duration of Hospital } \\
\text { Stay (days) } \\
\text { Range } \\
\text { Meen } \pm \text { SD }\end{array}$ & $\begin{array}{l}2.3 \\
2.96+0.198\end{array}$ & $\begin{array}{l}2.12 \\
3.36+1.827\end{array}$ & 0130 \\
\hline
\end{tabular}

MI=Myocardial Infarction; $\quad \mathrm{CVA}=$ Cerebrovascular Accidents; $\mathrm{SD}=$ Standard Deviation. P Value of $<0.05$ was considered significant.

\section{Patient Characteristics}

The patients in this study were relatively young (mean age $53 \pm 10.3$ _years) compared to the patients cohorts of similar multivessel stenting studies. For example, Moussa et. al. ${ }^{14}$ reported results of multivessel stenting in 100 patients, the mean age of the patient population was $59 \pm 9$ years; the series of Cowley et al. ${ }^{15}$ had a mean age of $55 \pm 10$ years whereas the mean age of the patients in the ARTS ${ }^{19}, \operatorname{SoS}^{18}$, BARI ${ }^{17}$ were $>60$ years.

Female patients constituted a very small fraction in the current study ( $6 \%$ overall) whereas most of the reports referred to above had a female population ranging from $20-30 \%$. The reason for this low proportion of females in the present study is poorly understood, but might be socio-cultural. CAD in females gets much less attention than in males, both during diagnosis and therapy.

Diabetics constituted $40 \%$ of the total study sample, a very high percentage compared to the $23-24 \%$ of Kornowski et. al. ${ }^{16}, 24-25 \%$ of the BARI ${ }^{17}$ investigation, and higher than the ARTS ${ }^{19}$ trial results (14-16\% diabetics). The SoS 18 trial had the lowest percentage of diabetics (14-16\%). Interestingly however, both these studies reported a higher percentage of three vessel disease (38-47\% in SoS and 30$33 \%$ in ARTS $)^{19}$, whereas the BARI ${ }^{17}$ study population with a high percentage of diabetics also reported a high (40$41 \%$ ) proportion of triple vessel disease patients.
Considering all the above statistics, the prevalence of triple vessel disease in the present study (24\%, 12 patients) may be considered low. The prevalence of two-vessel disease however in the present study is comparable to the above studies (ranging from 53 to $68 \%$ ).

Hypertension figured high in the multivessel stenting group, compared to the results of the French Monocentric Study Carrie et. al. ${ }^{20}$ at $31 \%$ but was comparable to those of $\operatorname{ARTS}^{19}(45 \%), \operatorname{SoS}^{18}(43 \%)$ and the BARI ${ }^{17}$ study on NHLBI $^{6}$ Registry (49\%). The incidence of hypertension was significantly higher in the multivessel stenting group (17 vs. 28 patients, $p$ value 0.044 ).

\section{Angiographic Characteristics}

Analysis of the clinical CAD status of the patients shows that a high proportion of patients had prior history of MI (overall incidence $54 \%$ ), similar to that in $\mathrm{BARI}^{17}$, but slightly higher than $\operatorname{ARTS}^{19}(44 \%)$ and $\operatorname{SoS}^{18}(44 \%)$ and the series of Kornowski ${ }^{16}$ et al. (47\%).

The LAD was involved in the highest percent of lesions in both the groups, followed by RCA and LCX in that order. Similar distribution of lesions was seen in the SoS ${ }^{18}$ trial, whereas in ARTS $^{19}$ trial RCA and LCX lesions had equal incidence following LAD, and in ERACI trial LAD was the predominant vessel involved followed by LCX and RCA in that order. In the Kornowski ${ }^{16}$ series, RCA lesions predominated whereas LAD and LCX followed in that order. The multivessel stenting group had a significantly higher number of LCX and RCA lesions ( $p$ value $\leq 0.001$ ) whereas LAD lesion was significantly higher ( $p$ value 0.013 ).

The type of lesion in the present study showed a higher proportion of A/B1 lesion compared to Moussa et al. (40\%) but similar to that of Kornowski ${ }^{16}$. There was no difference between the two groups with regards to type of lesion in the current study. Therefore, the present study contained patients with a higher risk lesion than the Kornowski ${ }^{16}$ series but lower risk group than Moussa ${ }^{14}$ et al. but a lower risk group than the BARI ${ }^{17}$ trial, where the type $\mathrm{C}$ lesion was present in $74 \%$ of cases.

\section{Procedural Variables and Adverse Events}

Outcomes of the present study revealed a high overall success rate of $99 \%$ by angiographic analysis. In one patient in the multivessel stenting group one attempted lesion could not by dilated, whereas two other lesions were successfully stented, giving a partially successful result and accounted for the difference between the two groups in terms of angiographic and procedural success. 


\section{Discussion}

This non-randomized, prospective observational study shows that single stage multivessel stenting is no more hazardous than and equally feasible with single vessel stenting. This study was carried out in the department of cardiology at the National Institute of Cardiovascular Diseases in a prospective, comparative observational design on 100 consecutive patients of single and multivessel stenting (50 in each group) as a single stage procedure.

The following are the observations and results obtained from the study -

Analysis of the procedural and outcome variables showed that both groups had comparable indications of stenting (elective $46 \%$ vs. $50 \%$ and provisional $54 \%$ vs. $50 \%$ in the SVS and MVS group respectively, $p$ value for the difference 0.841).

Comparison of the in-hospital adverse events between SVS and MVS group showed no death, periprocedural MI, tamponade, CVA, heart failure or cardiogenic shock, vascular access site complications like occlusion, dissection, A-V fistula in any group. However minor adverse events occurred at an overall rate of $6 \%$ in SVS group and $12 \%$ in MVS group, consisting of transient hypotension not requiring ionotropic or IABP support in $2 \%$ of SVS group and 45 of MVS group. Arrhythmia of transient nature responding to IV drugs only without necessity of DC Shock or CPR or long term antiarrhythmic medications occurred in $4 \%$ of SVS group and $6 \%$ of MVS group patients. One patient in the MVS group developed transient renal failure requiring prolonged hospital observation with conservative management, not requiring renal replacement therapy. Local bleeding at vascular access site occurred in 45 of SVS group and $6 \%$ of MVS group although none required surgery for such complications. The difference in the proportion of events in the two groups was not statistically significant in any category ( $p$ value 0.558 for hypotension, 0.646 for arrhythmia. 0.645 for renal failure, 0.646 for bleeding complications.

\section{Conclusion}

In conclusion, multivessel stenting is a feasible procedure in a large subset of multivessel disease patients without significant increase in adverse events or duration of hospital stay with a high degree of angiographic, procedural and clinical success.

\section{References}

1. Belle EV. Perie M, Branne D, et al. 2002. 'Effects of coronary stenting in vessel patency and long-term clinical outcome after Percutaeneous coronary revascularization in diabetic patients', J Am Coll Cardiol; 40 (3): 410-17
2. Boccara A, Benamer H, Juliard JM, et al. 'A randomized trial of a fixed high dose versus a weight adjusted low dose of heparin during coronary angioplasty', Eur Heart J, 1997; 18: 631-35.

3. Carrie D, Elbaz M, Puel J, et al. 'Five-year outcome after coronary Angioplasty Versus bypass Surgery in Multivessel Coronary Artery Disease-Results from the French Monocentric Study', Circulation, 1997:96 (Suppl II), II-1- II-6.

4. Cowley MJ, Vetrovec GW, Disiascio G et al. 'Coronary Angioplasty of multiple vessels : Short-term outcome and long-term results', Circulation, 1995; 72 (6) : 1314-20.

5. Cutlip DE, Leon MB, Ho KK, et al. 'Acute and nine-month clinical outcomes after "suboptimal" coronary stenting: Results from the STent Anti-thrombotic Regimens Study (STARS) Registry', J Am Coll Cardiol 1999; 34:698-06.

6. Detre KM, Holmes DR, Holubkov R, et al. 'Incidence and consequences of periprocedural occlusion: The 1985-86 National Heart, Lung and Blood Institute Percutaneous Transluminal Coronary Angioplasty Registry', Circulation, 1990; $82: 739-50$.

7. Dorros G, Lewin RF, Janke LRN, 'Multiple Lesion Transluminal Coronary Angioplasty in single and Multivessel Coronary Artery Disease: Acute Outcome and Long-term Effect' J Am Coll Cardiol, 1987;10 : 1007-13.

8. Gruberg L, Nikolsky E and Beyer R, 'Stenting in patients with multivessel Disease : The New Eon?', J invasive Cardiol, 2002; 14 (1) :06-08.

9. Hamm CW for the TRUST Study Group 'A multicenter, randomized trial comparing silicon carbide coated stents with stainless steel stents in acute coronary syndromes (TRUST Study)', Circulation, 2001;104: (Suppl II): II-464.

10. Hamm CW. Reimers J, Ischinger $\mathrm{T}$ et al., 'A randomized study of coronary angioplasty compared with bypass in patients with symptomatic multivessel coronary disease', $N$ Eng J Med, 1994; 1 (331) :1037-43.

11. Heuser RR, Lopez A, Kuntz R et al., 'For the SMART trial investigators,. SMART: The microstent's ability to limit restenosis trial', Catheter Cardiovasc Intervent, 2001; 52 : 269-77.

12. Holmes DR Jr, Lansky A, Kuntz R, et al. 'The PARAGON Stent study: A randomized trial of a new matensitic nitinol stent versus the Palmas-Schatz for treatment of complex native coronary arterial lesions', Am J Cardiol,2000; 86: 1073-79.

13. Holmes DR, Berger PB 'Complex and multivessel dilation', In Textbook of Interventional Cardiology. $2^{\text {nd }}$ edn, Topol EJ, WB Saunders, Philadelphia, 1994 : 231-50.

14. Moussa I, Reimers B, Moses J, et al. 'Long-term Angiographic and Clinical Outcome of Patients undergoing Multivessel Coronary Stenting', Circulation, 1997; 96: 873-79. 
15. Cowley MJ, Vetrovec GW, Disiascio G et al. 'Coronary Angioplasty of multiple vessels : Short-term outcome and long-term results', Circulation, 1995; 72 (6) : 1314-20.

16. Kornowski R, Mehran R, Satler LF et al. 'Procedural Results and late Clinical Outcomes Following Multivessel coronary stenting', J Am Coll Cardiol,1999; 33: (2) : 420-26.

17. The Bypass Angioplasty Revascularization Investigation (BARI) investigators. Comparison of Coronary Bypass Surgery with Angioplasty in Patients with Multivessel Disease. N Eng J Med; 1996; 335: 217-25.

18. The SoS Investigators. 'Coronary artery bypass surgery versus percutaneous coronary intervention with stent implantation in patients with multivessel coronary artery disease (the Stent or Surgery trial): a randomized controlled trial', The Lancet, 2002; 360 : 965-70.

19. Abizaid A, Costa MA, Centemero M, et al. 'Clinical and Economic Impact of Diabetes Mellitus on Percutaneous and Surgical Treatment of Multivessel Coronary Disease Patients: Insights from the Arterial Revascularization therapy Study (ARTS) Trial', Circulation, 2001; 104 : 533-38.

20. Carrie D, Elbaz M, Puel J, et al. 'Five-year outcome after coronary Angioplasty Versus bypass Surgery in Multivessel Coronary Artery Disease - Results from the French Monocentric Study', Circulation, 1997; 96 (Suppl II): II-1 II-6. 